\title{
Analysis of utilization patterns and associated costs of the breast imaging and diagnostic procedures after screening mammography
}

This article was published in the following Dove Press journal:

ClinicoEconomics and Outcomes Research

\author{
Anna Vlahiotis' \\ Brian Griffin² \\ A Thomas Stavros ${ }^{3}$ \\ Jay Margolis' \\ 'Value Based Care, Outcomes \\ Research, Truven Health Analytics, \\ an IBM Company, Bethesda, MD \\ USA; ${ }^{2}$ Value Based Care, Outcomes \\ Research, Truven Health Analytics, \\ an IBM Company, Newark, NJ, USA; \\ ${ }^{3}$ Seno Medical Instruments, Inc., San \\ Antonio, TX, USA
}

Background: Little data exist on real-world patterns and associated costs of downstream breast diagnostic procedures following an abnormal screening mammography or clinical exam. Objectives: To analyze the utilization patterns in real-world clinical settings for breast imaging and diagnostic procedures, including the frequency and volume of patients and procedures, procedure sequencing, and associated health care expenditures.

Materials and methods: Using medical claims from 2011 to 2015 MarketScan Commercial and Medicare Databases, adult females with breast imaging/diagnostic procedures (diagnostic mammography, ultrasound, molecular breast imaging, tomosynthesis, magnetic resonance imaging, or biopsy) other than screening mammography were selected. Continuous health plan coverage without breast diagnostic procedures was required for $\geq 13$ months before the first found breast diagnostic procedure (index event), with a 13-month post-index follow-up period. Key outcomes included diagnostic procedure volumes, sequences, and payments. Results reported descriptively were projected to provide US national patient and procedure volumes.

Results: The final sample of 875,526 patients was nationally projected to $12,394,432$ patients annually receiving $8,732,909$ diagnostic mammograms (53.3\% of patients), 6,987,399 breast ultrasounds ( $42.4 \%$ of patients), and 1,585,856 biopsies ( $10.3 \%$ of patients). Following initial diagnostic procedures, $49.4 \%$ had second procedures, $20.1 \%$ followed with third procedures, and $10.0 \%$ had a fourth procedure. Mean (SD) costs for diagnostic mammograms of US\$349 (\$493), ultrasounds US\$132 (\$134), and biopsies US\$1,938 (\$2,343) contributed US\$3.05 billion, US\$0.92 billion, and US \$3.07 billion, respectively, to annual diagnostic breast expenditures estimated at US\$7.91 billion. Conclusion: The volume and expense of additional breast diagnostic testing, estimated at US\$7.91 billion annually, underscores the need for technological improvements in the breast diagnostic landscape.

Keywords: breast cancer, mammography, imaging, diagnosis, health care utilization, expenditures

\section{Summary}

This study, using health care claims data from 2011 to 2015, estimated that follow-on breast diagnostic procedures in the US amounted to an annual expenditure of $\$ 7.91$ billion (USD), annually affecting $12,394,432$ patients who received 8,732,909 diagnostic mammograms, 6,987,399 breast ultrasounds, and 1,585,856 biopsies, underscoring the need for diagnostic modalities providing better specificity and greater diagnostic confidence that can lower the health care expenditures and shorten the patient's diagnostic journey.

\section{Background and objectives}

Breast cancer is the most common malignancy among women worldwide and the second leading cause of cancer-related deaths in females, with an estimated 292,130
Correspondence: Anna Vlahiotis Company, 7700 Old Georgetown Road, 6th Floor, Bethesda, MD 208I4, USA

Tel + I 3/43075306

Email avlahiot@us.ibm.com 
new cases diagnosed in the US in $2015 .{ }^{1-3}$ Survival rates have increased steadily over recent decades as earlier detection enables treatment at earlier stages when treatment is more effective and less costly. ${ }^{4-6}$ While evidence-based guidelines for breast cancer screening issued by several organizations in the US, including the American Cancer Society, National Comprehensive Cancer Network, US Preventive Services Task Force, American College of Radiology, and the Society for Breast Imaging, may differ on the timing (annually, biennially) and ages for screening (to begin at age 40 or 50 years, screening after age 74 years), ${ }^{7-13}$ controversy remains in balancing breast cancer screening costs with rates of detection, rates of false-positives or overdiagnoses, and reduction in mortality. ${ }^{14-16}$

Studies have estimated that $5 \%$ to over $20 \%$ of patients are subsequently recalled for follow-up procedures following their initial screening. ${ }^{17-20}$ Around $10 \%$ of abnormal screening mammograms $(<1 \%$ of those screened) are subsequently diagnosed as breast cancers. ${ }^{19,21}$ Patient recall extends the diagnostic journey through a series of one or more additional breast imaging and diagnostic procedures based on recommendations of the radiologist and guided by the American College of Radiology's Breast Imaging Reporting and Data System (BI-RADS), categorizing breast lesions on a scale of 0-6, before definitive diagnosis or no further need for additional imaging can be determined. The diagnostic imaging journey has evolved in recent years to increase the sensitivity of breast cancer imaging, which may include diagnostic mammography, tomosynthesis, ultrasonography (ultrasound), magnetic resonance imaging (MRI), or molecular breast imaging (MBI). ${ }^{22}$ Suspicious lesions (BI-RADS category 4 or 5 ) warranting a biopsy are found in $\sim 10 \%$ of those having an additional diagnostic imaging procedure. ${ }^{12,13,23}$

Women receiving a positive result from an abnormal screening mammogram not subsequently resulting in a breast cancer diagnosis are considered to have had a false-positive screening result, which adds potential psychological distress, additional health care visits, diagnostic tests, and associated costs. Despite improvements in technology, the rate of falsepositive results remains high, estimated to occur in 13\%-16\% of recalls and as high as $61 \%$ of patients over a cumulative 10 -year period. ${ }^{16,24}$ Biopsies were performed in $25 \%-29 \%$ of patients with false-positive screening mammograms, with cumulative 10 -year biopsy exposure of $7 \%-9 \%$ of all screened patients. ${ }^{16,24}$

Published guidelines ${ }^{7-13}$ describe recommendations for the use and sequence of the available breast diagnostic procedures; yet, there is little literature published on the actual patterns of use seen in clinical practices and the costs of implementing these procedures. The objective of this study was to analyze the patterns of diagnostic breast imaging and diagnostic procedures used for patients recalled in real-world clinical settings (following screening mammography or other abnormal examination findings), including the frequency and volume of patients and procedures, the most common sequences in which procedures are performed, and the associated health care expenditures.

\section{Materials and methods Data source}

Administrative health care claims data from the Truven Health MarketScan ${ }^{\circledR}$ 2011-2015 Commercial and Medicare Supplemental Databases were used for this study, providing a nationally projectable large and diverse real-world patient sample. These databases contain the complete longitudinal records of inpatient and outpatient services for $\sim 35$ million commercially insured and over 3 million Medicare-eligible patients in each of the study years, covered under a variety of health plans, including dates of service, places of service, and all payments. All database records and data are statistically de-identified and fully compliant with the US patient confidentiality requirements set forth in Sections 164.514 (a)-(b)1 ii of the Health Insurance Portability and Accountability Act. As this study used only de-identified patient records and did not involve the collection, use, or transmittal of individually identifiable data, Institutional Review Board approval to conduct this study was not necessary.

\section{Patient selection}

Adult (aged 18+ years) females who had at least one medical claim for a breast imaging or breast diagnostic procedure (diagnostic mammography, ultrasound, MBI, tomosynthesis, MRI, or biopsy) between January 1, 2012 and June 30, 2014 were selected. Coding for these procedures is provided in Table 1. The first found diagnostic procedure date was labeled the index date. At least 13 months of continuous health plan coverage was required before the index date (baseline period) and after the index date (follow-up period). The 13-month baseline and follow-up periods allow 1 year plus an additional 30 days for capturing follow-on services delayed beyond recommended clinical guidelines (i.e., repeating procedures in 12 months) to enable reimbursement by payers. The complete study period spanned January 1, 2011 through July 31, 2015, which included 13-month baseline and follow-up periods surrounding the 2012-2014 patient selection window. 
Table I Codes used to identify breast diagnoses and diagnostic procedures ${ }^{\mathrm{a}, \mathrm{b}}$

\begin{tabular}{|c|c|}
\hline Diagnosis or procedure & Codes/criteria \\
\hline Breast cancer & ICD-9-CM diagnosis codes I74.xx, I98.8I, 233.0, 238.3, or 239.3 \\
\hline Breast-related diagnosis & $\begin{array}{l}\text { ICD-9-CM diagnosis codes 174.0x-174.9x; 198.8I, 233.0x, 238.3x, 239.3x, 610.0x-6I2.1x, 675.80, 757.6x, 793.89, } \\
\text { 879.0x, 879.1x, VI0.3x, VI6.3x, V5I.0x, V76.10-V76.19, V84.0I }\end{array}$ \\
\hline Diagnostic mammography & CPT codes 77055 or 77056 ; or ICD-9-CM procedure code 87.36 or 87.37 ; or HCPCS code G0204 or G0206 \\
\hline Tomosynthesis & $\begin{array}{l}\text { CPT code } 77057 \text { or HCPCS code G0202 in combination with CPT code } 76499 \text { if prior to January I, 2015; CPT code } \\
77057 \text { or HCPCS code G0202 in combination with CPT code } 77063 \text { if after January I, 20I5; CPT code } 77055 \text { or } \\
77056 \text {, or HCPCS code G0204 or G0206 in combination with CPT code } 76499 \text { if prior to January I, 20I5; HCPCS } \\
\text { code G0204 or G0206 in combination with HCPCS code G0279 if after January I, } 2015 \text { (Medicare); CPT code } 77055 \\
\text { or } 77056 \text {, in combination with CPT code } 7706 \text { I or } 77062 \text {, or HCPCS code G0204 or G0206 in combination with } \\
\text { CPT code } 7706 \text { I or } 77062 \text { if after January I, } 2015 \text { (commercial) }\end{array}$ \\
\hline Ultrasound & CPT code 7664 I, 76642,76645 , or revenue code $30 \mathrm{I} 4 \mathrm{~F}$ \\
\hline $\mathrm{MBI}$ & CPT code 78800 or 78801 \\
\hline MRI & CPT code $77022,76498,77058$, or 77059 ; or HCPCS codes C8903-C8908 or CPT code $0159 T$ \\
\hline Biopsy ${ }^{c, d}$ & 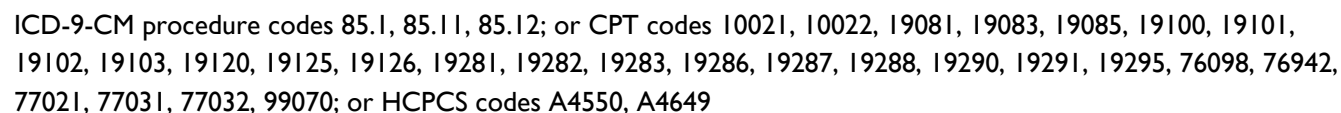 \\
\hline
\end{tabular}

Notes: aNote that screening mammography was not used as a patient selection criterion; however, subsequent analyses identified patients having a screening mammogram during the pre-index period, identified in claims using ICD-9-CM procedure codes V76.II, V76.12, V76.19, HCPCS code G0202, or CPT code 77057. ${ }^{\circ}$ This table shows the coding used over the time period of this study. Note that numerous CPT codes and code definitions changed during this time. 'Biopsy coding was for diagnostic breast biopsy only, and did not include axillary biopsies or preoperative needle localization/seed/SAVl ${ }^{\circledR}$ localization. ${ }^{d B i o p s y}$ coding was used to identify surgical biopsy procedures as well as ancillary procedures associated with the actual surgical biopsy.

Abbreviations: CPT, Common Procedural Terminology code; HCPCS, Healthcare Common Procedure Coding System code; ICD-9-CM, International Classification of Diseases, Ninth Revision, Clinical Modification, procedure code; MBI, molecular breast imaging; MRI, magnetic resonance imaging.

Patients who had one of the diagnostic breast imaging procedures (including biopsies) during the 13-month baseline period or who had breast surgery within 90 days of a breast cancer diagnosis (Table 1) during the baseline period were excluded.

\section{Study measures}

Baseline demographic variables included age, health plan type, primary payer (commercial or Medicare), urban/rural residence, and geographic location within the nine US Census Bureau divisions. ${ }^{25}$

Key outcomes reported during the follow-up period included diagnostic procedure volume (total procedure count and number of patients with a procedure) and health care payments per procedure. Biopsies were further stratified by imaging guidance type (ultrasound guided and guided by any other, which included stereotactic and MRI guidance) and specimen collection type (surgical, core, vacuum-assisted, and fine needle aspiration).

Another key outcome was analysis of sequences in which diagnostic procedures occurred across the study population, referred to as "real-world care paths", reported as the number (and percentage) of patients with a particular procedure as their first procedure, the number who then progressed to a second particular procedure, and so on. Sequences were analyzed as point prevalences, that is, the proportion of the study population receiving a particular procedure at different points of diagnostic procedure progressions. Procedures occurring on the same day were arbitrarily prioritized in the following order: diagnostic mammogram, tomosynthesis, ultrasound, MBI, biopsy, MRI. The two most common real-world care paths are shown in Figure 1. It should be noted that screening mammography was not used as a patient selection criterion; however, subsequent analyses identified patients having a screening mammogram during the pre-index period.

Health care payments were measured using the financial fields in medical claims incurred during the 13-month followup period, expressed in 2015 constant dollars, adjusted using the Medical Care component of the Consumer Price Index. Health care payments included the gross covered payments by all payers for all health care services or products including the group health plan's payment, the Medicare-covered portion of payment (for Medicare-covered patients), deductibles, copayments, other plans' or employers' coordination-of-benefit payments, and any out-of-pocket patient expenses. Payments for services provided under capitated arrangements were imputed based on the average payments for non-capitated claims at the region, year, and procedure level within the MarketScan databases. Services ancillary to biopsy procedures (anesthesia, pathology, and physician office visits) were also reported, defined as services provided within 3 days of a biopsy claim that included a breast-related diagnosis (Table 1). Imaging (e.g., mammogram or ultrasound) performed following biopsy to confirm the placement of 


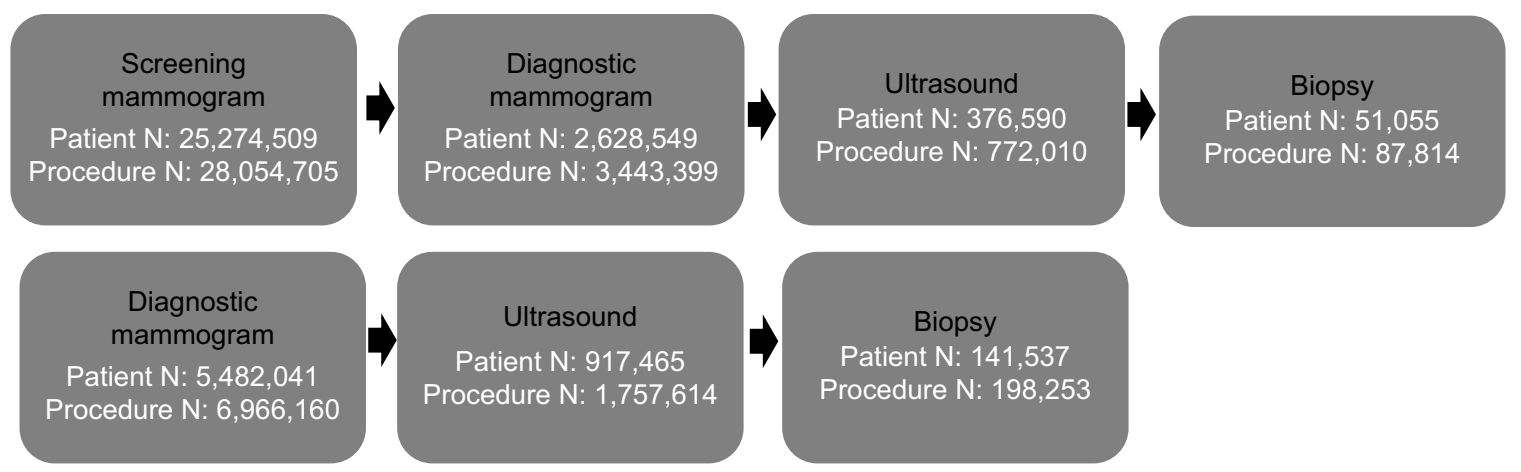

Figure I Two most common breast imaging and diagnostic care paths, with projected annual US patient and procedure volumes ${ }^{\mathrm{a}, \mathrm{b}}$.

Notes: aPatient and procedure volumes only reflect those of the two most common care paths and do not equal the total volume for all procedure types. ${ }^{b}$ These are annual patient and procedure volumes, projected to the US national population.

the post-biopsy markers was not coded as biopsy related in claims data, and so was not included as a biopsy ancillary service. Some biopsy payments may have included ancillary services bundled as part of the biopsy claim.

\section{US national projections}

The frequency and volume of breast diagnostic procedures, and volumes of patients in real-world care paths, were projected to derive US national patient and procedure volumes associated with breast diagnostic imaging by applying nationally projected figures from two Truven Health data sources, Outpatient View and Inpatient View, which provide utilization rates by calendar period, payer, age, gender, site, and procedure. The utilization rates were built directly from public and private claims streams, including national federal surveys. These rates were multiplied by their appropriate populations at the ZIP-code level to yield procedure volume estimates for the US total inpatient and outpatient market for all procedures of interest. The projected populations and volumes are representative of the 2015 US adult female population and all insurance coverages, including commercial, Medicare, other government insurances, and uninsured.

All analyses were conducted using Statistical Analysis Software $\left(\mathrm{SAS}^{\circledR}\right)$ version 9.4 (SAS Institute Inc., Cary, NC, USA).

\section{Results}

The study selection criteria identified a final sample of 875,526 patients meeting all the criteria (Table 2). The study cohort's mean age was 52.5 years with $69.9 \%$ of patients between 45 and 64 years old (only $0.8 \%$ of the sample was younger than 35 years of age). Most patients resided in urban areas $(86.0 \%)$, and $90 \%$ had commercial insurance coverage (Table 3). Patient counts, procedure frequencies, and procedure volumes for this sample population were projected to the US national population.

Projecting these patients to the US population yielded a total of 12,394,432 female patients who had received at least one of the designated diagnostic breast procedures during the 13-month follow-up period (Tables 3 and 4). Projected patients more closely echoed the US distribution for payers (commercial 75.6\%, Medicare eligible 20.6\%) and geographic distribution. A total of 18,903,337 breast imaging and biopsy procedures were received by the nationally projected population during their 13-month follow-up period. The most commonly performed imaging procedure was diagnostic mammography, with $8,732,910$ procedures performed in $6,603,297$ patients $(53.3 \%$ of patients) and $6,987,399$ diagnostic ultrasound procedures performed in $5,253,354$ patients ( $42.4 \%$ of patients). The newer breast imaging modalities were less commonly performed, with 5\% or fewer patients experiencing tomosynthesis, MBI, or breast MRI, which may be expected considering access to devices or facility availability and insurance coverage policies relative to the years of our study data. An estimated 1,585,856 biopsies were performed in $1,277,844$ patients ( $10.3 \%$ of patients) during the follow-up period. The most common approaches were ultrasound-guided core biopsies $(1,007,417$ biopsies [63.5\%] in 949,118 patients [74.3\%]) and ultrasound-guided localization of surgical biopsies (311,426 biopsies [19.6\%] in 279,323 patients [21.9\%]). Ultrasound guidance was used in $87 \%$ of biopsies (1,406,006 of $1,585,856$ biopsies).

Sequences of procedures in the breast diagnostic care path were quite variable, as shown in Table 5. The most common first diagnostic procedures were diagnostic mammography for $88.0 \%$ of patients and ultrasound for $10.8 \%$. Following the first procedure, $49.4 \%$ of patients proceeded to a second procedure, which was most often ultrasound (57.4\%) or 
Table 2 Attrition

\begin{tabular}{|c|c|c|}
\hline Patient selection criteria & $\mathbf{n}$ & $\%$ \\
\hline Patients in MarketScan ${ }^{\circledR}$ Commercial and Medicare Research Databases from January I, 20II-July 3I, 20I5 & $131,603,746$ & \\
\hline Female & $67,754,615$ & 100.0 \\
\hline Received a screening mammography ${ }^{b}$ & II,687,689 & 17.3 \\
\hline $\begin{array}{l}\text { Received a breast imaging diagnostic procedure (diagnostic mammography, ultrasound, MBI, tomosynthesis, MRI, } \\
\text { or biopsy) })^{c}\end{array}$ & $2,168,710$ & 3.2 \\
\hline Continuous health plan coverage $\geq 13$ months prior to the index date ${ }^{d}$ & $1,544,629$ & 2.3 \\
\hline Aged $\geq 18$ years at index & $\mathrm{I}, 275,804$ & 1.9 \\
\hline $\begin{array}{l}\text { No inpatient or outpatient claims with a procedure code indicating any diagnostic breast imaging in the pre-index } \\
\text { period (except screening mammography) }\end{array}$ & $\mathrm{I}, 040,60 \mathrm{I}$ & I.5 \\
\hline No inpatient or outpatient claims with a new breast cancer diagnosis at any time in the pre-index period & $1,039,473$ & 1.5 \\
\hline Patients with $\geq 13$ months of continuous eligibility & 875,526 & 1.3 \\
\hline
\end{tabular}

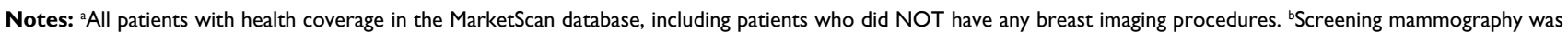
identified using ICD-9-CM procedure codes V76.II, V76.12, V76.19, HCPCS code G0202, or CPT code 77057. 'Patients receiving breast imaging diagnostic procedures were not required to have had a claim for screening mammography. ${ }^{\mathrm{d}}$ The index date is the first medical claim date for any diagnostic mammography, ultrasound, MBI, tomosynthesis, MRI, or biopsy performed.

Abbreviations: CPT, Common Procedural Terminology code; HCPCS, Healthcare Common Procedure Coding System code; ICD-9-CM, International Classification of Diseases, Ninth Revision, Clinical Modification, procedure code; MBI, molecular breast imaging; MRI, magnetic resonance imaging.

diagnostic mammography (33.5\%). Biopsy was performed for $6.3 \%$ of patients following their first diagnostic imaging procedure. Of the patients receiving a second procedure, $40.8 \%$ experienced a third round of diagnostic testing, most commonly diagnostic mammography $(54.2 \%)$ or ultrasound (27.4\%). Biopsy was performed for $13.8 \%$ of patients experiencing a third round of diagnostics. Half of the patients with three diagnostic procedures went to a fourth round of procedures (Table 5).

Paid amounts for breast diagnostic procedures for all patients are shown in Table 6. A further stratification of the paid amounts by payer (commercial or Medicare) may be found in Table S1. The least expensive procedure was ultrasound, with mean (SD) paid amount of \$132 (\$134) per procedure over all patients. The most common procedure, diagnostic mammograms, averaged \$349 (\$493). Biopsies were the most expensive procedures at an overall mean (SD) cost of $\$ 1,938$ (\$2,343), with ultrasound-guided localization of surgical biopsies being the most expensive image-guided specimen collection type at $\$ 1,909(\$ 2,199)$. Although less commonly performed (data not shown), MRI-guided biopsies were associated with higher mean (SD) payments $(\$ 1,804$ $[\$ 1,689])$ than ultrasound-guided core biopsy procedures $(\$ 1,032$ [\$1,200]). Ultrasound-guided fine needle aspiration biopsy procedures were the least expensive at \$249 (\$467) and were less commonly performed. Ancillary services for biopsy procedures combined for an average additional $\$ 3,120$, including office visits at a mean (SD) expenditure of $\$ 735$ (\$891), pathology services $\$ 1,264(\$ 2,463)$, and anesthesia $\$ 1,120(\$ 1,146)$. (Authors' note: Health care cost data have long been observed to exhibit substantial skewness with long right-sided tails, commonly resulting in large SDs often approaching or exceeding the value of the mean. ${ }^{26}$ )

\section{Discussion}

This study examined breast diagnostic procedure utilization occurring in real-world clinical practices across a large geographically diverse population of women in the US during their first year of a diagnostic journey that may have included one or more of five available diagnostic breast imaging procedures and/or biopsy following either screening mammography or as a result of abnormal findings during clinical examination in the pre-index period. Data were extrapolated to the US population of women with commercial or Medicare coverage, with a resulting projected population of 12,394,432 affected individuals. The three most common components of the breast diagnostic care paths were diagnostic mammography, ultrasound, and biopsy. Using the mean paid amounts for each of these procedures (Table 6), the national expenditure for 8,732,910 diagnostic mammograms, 6,987,399 ultrasounds, and 1,585,856 biopsies is estimated to cost $\$ 3.05$ billion, $\$ 0.92$ billion, and $\$ 3.07$ billion, respectively, contributing with the other diagnostic procedures (tomosynthesis, MBI, MRI) to an estimated annual expenditure of $\$ 7.91$ billion.

Follow-up for patients with abnormal screening mammography results is critical. ${ }^{12}$ Routine clinical practice and associated guidelines call for further imaging studies prior to invasive biopsy procedures upon finding a suspicious screening mammogram result. ${ }^{7,8,11}$ Our data confirm this practice, with diagnostic mammography performed for $88.0 \%$ of initial diagnostic workups. Following the first diagnostic procedure, 
Table 3 Demographic characteristics of patients

\begin{tabular}{|c|c|c|}
\hline \multirow{2}{*}{$\begin{array}{l}\text { Patient characteristic } \\
\text { Age (mean }[S D] \text { ) }\end{array}$} & \multicolumn{2}{|c|}{ Study cohort, $N=875,526$} \\
\hline & 52.5 & 9.5 \\
\hline \multicolumn{3}{|l|}{ Age group, years (n, \%) } \\
\hline $18-34$ & 6,584 & 0.8 \\
\hline $35-44$ & 189,845 & 21.7 \\
\hline $45-54$ & 325,154 & 37.1 \\
\hline $55-64$ & 276,735 & 31.6 \\
\hline $65-74$ & 56,443 & 6.4 \\
\hline $75+$ & 20,765 & 2.4 \\
\hline \multicolumn{3}{|l|}{ Geographic region (n, \%) } \\
\hline New England & 47,963 & 5.5 \\
\hline Mid-Atlantic & 152,677 & 17.4 \\
\hline East North Central & 158,213 & 18.1 \\
\hline West North Central & 34,427 & 3.9 \\
\hline South Atlantic & 174,326 & 19.9 \\
\hline East South Central & 74,700 & 8.5 \\
\hline West South Central & 89,219 & 10.2 \\
\hline Mountain & 38,970 & 4.5 \\
\hline Pacific & 88,801 & 10.1 \\
\hline Unknown & 16,230 & 1.9 \\
\hline \multicolumn{3}{|c|}{ Urban vs rural residence $(n, \%)$} \\
\hline Urban residence & 750,147 & 85.7 \\
\hline Rural residence & 109,612 & 12.5 \\
\hline Unknown & 15,767 & 1.8 \\
\hline \multicolumn{3}{|l|}{ Insurance plan type (n, \%) } \\
\hline Comprehensive & 43,286 & 4.9 \\
\hline HMO & 6,756 & 0.8 \\
\hline POS & 107,335 & 12.3 \\
\hline PPO & 69,023 & 7.9 \\
\hline CDHP & 517,235 & 59.1 \\
\hline Other & 3,606 & 0.4 \\
\hline \multicolumn{3}{|l|}{ Primary payer (n, \%) } \\
\hline Commercial & 776,161 & 88.7 \\
\hline Medicare & 78,620 & 9.0 \\
\hline Transition ${ }^{\mathrm{a}}$ & 20,745 & 2.4 \\
\hline \multicolumn{3}{|l|}{ Presence of capitation (n, \%) } \\
\hline Non-capitated patients & 816,933 & 93.3 \\
\hline Capitated patients & 58,593 & 6.7 \\
\hline \multicolumn{3}{|l|}{ Index year $(n, \%)$} \\
\hline 2012 & 327,651 & 37.4 \\
\hline 2013 & 319,969 & 36.5 \\
\hline 2014 & 227,906 & 26.0 \\
\hline
\end{tabular}

Note: aPatients who transitioned from commercial health insurance only to Medicare-based coverage during the follow-up period.

Abbreviations: CDHP, consumer-driven health plan; $\mathrm{HMO}$, health maintenance organization; POS, point of service; PPO, preferred provider organization.

around half of the patients proceed to a second imaging procedure, most commonly ultrasound $(57.4 \%$ of second line procedures) or diagnostic mammography (33.5\%), or biopsy $(6.3 \%)$. It is possible that some diagnostic mammograms may have been coded as screening mammograms, either mistakenly or to obviate insurance coverage issues, which may account for some patients $(0.3 \%)$ with biopsy as a first diagnostic procedure.

Biopsy is the most expensive individual procedure and the costliest overall for health plans. This study found the
Table 4 Patient and procedure volume in 13-month follow-up (projected) $^{\mathrm{a}}$

\begin{tabular}{|c|c|c|}
\hline Procedure & Counts & $\%$ \\
\hline \multicolumn{3}{|l|}{ Any diagnostic procedure } \\
\hline Number of patients (n, \%) & $12,394,432$ & 100.0 \\
\hline Number of procedures performed (n) & $18,903,337$ & \\
\hline Pre-index screening mammography (n, \%) & $10,543,647$ & 85.1 \\
\hline \multicolumn{3}{|l|}{ Diagnostic mammography } \\
\hline Number of patients (n, \%) & $6,603,297$ & 53.3 \\
\hline Number of procedures performed (n) & $8,732,910$ & \\
\hline \multicolumn{3}{|l|}{ Tomosynthesis } \\
\hline Number of patients (n, \%) & 145,423 & 1.2 \\
\hline Number of procedures performed (n) & 152,504 & \\
\hline \multicolumn{3}{|l|}{ Ultrasound } \\
\hline Number of patients (n, \%) & $5,253,354$ & 42.4 \\
\hline Number of procedures performed (n) & $6,987,399$ & \\
\hline \multicolumn{3}{|l|}{ Molecular breast imaging } \\
\hline Number of patients (n, \%) & 13,796 & 0.1 \\
\hline Number of procedures performed (n) & $|4,25|$ & \\
\hline \multicolumn{3}{|l|}{ Magnetic resonance imaging } \\
\hline Number of patients (n, \%) & 615,738 & 5.0 \\
\hline Number of procedures performed (n) & 700,330 & \\
\hline \multicolumn{3}{|l|}{ Biopsy } \\
\hline Number of patients $(\mathrm{n}, \%)$ & $\mathrm{I}, 277,844$ & 10.3 \\
\hline Number of procedures performed (n) & $\mathrm{I}, 585,856$ & \\
\hline \multicolumn{3}{|l|}{ Surgical biopsy } \\
\hline \multicolumn{3}{|l|}{ Ultrasound-guided localization } \\
\hline Number of patients $(\mathrm{n}, \%)$ & 279,323 & 2.3 \\
\hline Number of procedures performed (n) & 311,426 & \\
\hline \multicolumn{3}{|l|}{ Other surgical } \\
\hline Number of patients (n, \%) & 33,644 & 0.3 \\
\hline Number of procedures performed (n) & 34,524 & \\
\hline \multicolumn{3}{|l|}{ FNA biopsy } \\
\hline \multicolumn{3}{|l|}{ Ultrasound-guided FNA } \\
\hline Number of patients $(\mathrm{n}, \%)$ & 83,766 & 0.7 \\
\hline Number of procedures performed (n) & 87,163 & \\
\hline \multicolumn{3}{|l|}{ Other FNA } \\
\hline Number of patients (n, \%) & 25,027 & 0.2 \\
\hline Number of procedures performed (n) & 26,103 & \\
\hline \multicolumn{3}{|l|}{ Core biopsy } \\
\hline \multicolumn{3}{|l|}{ Ultrasound-guided core } \\
\hline Number of patients (n, \%) & 949,118 & 7.7 \\
\hline Number of procedures performed (n) & $1,007,417$ & \\
\hline
\end{tabular}

Note: aTable S2 provides reference figures for the 2015 US Census estimates of all adult women and health care coverages.

Abbreviation: FNA, fine needle aspiration.

average price per biopsy of $\$ 1,938$, which we feel is conservative, since this amount may not always include the mean paid amounts for follow-up office visits (\$735), pathology $(\$ 1,264)$, or anesthesia $(\$ 1,120)$, unless separately billed. ${ }^{27}$ Our rate of $10.3 \%$ for breast biopsies following recall is in agreement with several other independent studies..$^{12,13,19,23}$ The published rates of false-positive biopsies are high. A recent study of false-positive screening mammograms estimated that $24.9 \%$ of patients with false-positive screening procedures had received biopsies. ${ }^{16} \mathrm{~A}$ National Cancer Institute analysis 
Table 5 Diagnostic procedure sequences ${ }^{\mathrm{a}}$

\begin{tabular}{|c|c|c|c|c|c|c|c|}
\hline & $\begin{array}{l}\text { All } \\
\text { patients, \% }\end{array}$ & $\begin{array}{l}\text { Diagnostic } \\
\text { mammography, \% }\end{array}$ & Tomosynthesis, \% & Ultrasound, \% & MBI, \% & MRI, \% & Biopsy, \% \\
\hline First diagnostic procedure & 100 & 88.0 & 0.1 & 10.8 & 0.04 & 0.8 & 0.3 \\
\hline $\begin{array}{l}\text { Patients receiving a second } \\
\text { procedure }\end{array}$ & 49.4 & 50.4 & 22.9 & 42.5 & 14.6 & 39.6 & 31.9 \\
\hline $\begin{array}{l}\text { Procedure received (second } \\
\text { procedure) }\end{array}$ & & 33.5 & 1.2 & 57.4 & 0.0 & 1.6 & 6.3 \\
\hline \multicolumn{8}{|l|}{ First to second procedure detail } \\
\hline To diagnostic mammography & & 32.9 & 50.0 & 36.9 & 67.9 & 57.4 & 68.2 \\
\hline To tomosynthesis & & 1.3 & 2.7 & 0.0 & 1.9 & 0.1 & 0.0 \\
\hline To ultrasound & & 58.2 & 44.6 & 54.2 & 5.7 & 16.7 & 14.0 \\
\hline To molecular breast imaging & & 0.0 & 0.0 & 0.0 & 17.0 & 0.0 & 0.3 \\
\hline To magnetic resonance imaging & & 1.4 & 2.2 & 1.8 & 5.7 & 22.9 & 10.7 \\
\hline To biopsy & & 6.2 & 0.5 & 7.0 & 1.9 & 2.8 & 6.7 \\
\hline $\begin{array}{l}\text { Patients with two procedures } \\
\text { receiving a third procedure }\end{array}$ & $40.8^{\mathrm{b}}$ & 35.7 & 79.5 & 40.4 & 40.9 & 55.1 & 60.7 \\
\hline $\begin{array}{l}\text { Procedure received (third } \\
\text { procedure) }\end{array}$ & & 54.2 & 0.6 & 27.4 & 0.1 & 3.9 & 13.8 \\
\hline \multicolumn{8}{|l|}{ Second to third procedure detail } \\
\hline To diagnostic mammography & & 36.6 & 4.6 & 62.6 & 61.9 & 69.0 & 67.8 \\
\hline To tomosynthesis & & 2.0 & 0.0 & 0.0 & 0.0 & 0.0 & 0.0 \\
\hline To ultrasound & & 45.9 & 94.5 & 18.2 & 15.9 & 17.1 & II.I \\
\hline To molecular breast imaging & & 0.0 & 0.0 & 0.1 & 1.6 & 0.3 & 0.2 \\
\hline To magnetic resonance imaging & & 2.5 & 0.4 & 2.7 & 6.3 & 3.1 & 16.3 \\
\hline To biopsy & & 13.0 & 0.4 & 16.4 & 14.3 & 10.5 & 4.6 \\
\hline $\begin{array}{l}\text { Patients with three procedures } \\
\text { receiving any fourth procedure }\end{array}$ & $49.6^{c}$ & 53.1 & 66.3 & 36.6 & 55.2 & 61.3 & 57.9 \\
\hline $\begin{array}{l}\text { Procedure received (fourth } \\
\text { procedure) }\end{array}$ & & 32.7 & 1.1 & 37.3 & 0.1 & 22.7 & 6.1 \\
\hline \multicolumn{8}{|l|}{ Third to fourth procedure detail } \\
\hline To diagnostic mammography & & 18.1 & 5.4 & 46.6 & 63.5 & 64.6 & 59.8 \\
\hline To tomosynthesis & & 1.8 & 0.0 & 0.1 & 0.0 & 0.0 & 0.0 \\
\hline To ultrasound & & 45.6 & 92.8 & 33.2 & 11.8 & 18.6 & 15.4 \\
\hline To molecular breast imaging & & 0.1 & 0.0 & 0.1 & 0.0 & 0.4 & 0.3 \\
\hline To magnetic resonance imaging & & 3.5 & 0.6 & 3.7 & 2.4 & 3.5 & 19.5 \\
\hline To biopsy & & 30.9 & 1.3 & 16.4 & 22.4 & 13.0 & 5.0 \\
\hline
\end{tabular}

Notes: a How to read Table 5: Example using diagnostic mammography. About $88 \%$ of all patients had diagnostic mammography as their first procedure. Of those with diagnostic mammography as their first procedure, $50.4 \%$ had any second procedure. Of all patients with any second procedure, $33.5 \%$ had diagnostic mammography. Of the patients with diagnostic mammography as their first procedure, $32.9 \%$ had diagnostic mammography as their second procedure, $1.3 \%$ had tomosynthesis, $58.2 \%$ had ultrasound, and so on. In the next section describing patients with two procedures receiving a third procedure, of all patients receiving diagnostic mammography as their second procedure, $35.7 \%$ had any third procedure. Of all patients with any third procedure, $54.2 \%$ had diagnostic mammography. Of the patients with diagnostic mammography as their second procedure, $36.6 \%$ had diagnostic mammography as their third procedure, $2.0 \%$ had tomosynthesis, $45.9 \%$ had ultrasound, and so on. This same logic applies to the next section (patients with three procedures receiving a fourth procedure). ${ }^{b} \mathrm{About} 40.8 \%$ of those patients receiving two procedures had a third procedure. This may also be stated that $20.1 \%$ of all patients received a third procedure. ${ }^{\text {About }} 49.6 \%$ of those patients receiving three procedures received a fourth procedure. This may also be stated that $10.0 \%$ of all patients received a fourth procedure.

Abbreviations: $\mathrm{MBI}$, molecular breast imaging; $\mathrm{MRI}$, magnetic resonance imaging.

of Breast Cancer Surveillance Consortium (BCSC) data through 2009 reported a positive predictive value (the rate of positive cancer detection following biopsy, PPV3) for breast biopsy of $29.0 \%$, implying a false-positive rate of $71.0 \% .{ }^{20} \mathrm{An}$ earlier study using BCSC data from 1996 to 2001 similarly found $26.9 \%$ of biopsies with invasive cancer and $6.3 \%$ with carcinoma in situ, thus $66.8 \%$ were noncancerous. Using the more recent BCSC estimate of false-positive biopsies puts the expenditure for false-positive biopsies at $\$ 2.18$ billion, a substantial cost assuming the estimated rate and cost of biopsies in our data. ${ }^{27}$

False-positives are a sensitive issue in the breast cancer diagnostic journey due to the impact on health care resources, expenditure, and psychosocial effects, with estimates ranging from $13.0 \%$ to $16.3 \%$ of initial recalls overall and as high as $61 \%$ of individual patients with screening mammographies over a cumulative 10-year period. ${ }^{16,24}$ The estimated annual cost of false-positive mammograms in the US was 
Table 6 Mean (SD) and median paid amounts for breast diagnostic procedures in US dollars

\begin{tabular}{lll}
\hline Diagnostic imaging procedure & Mean (SD) & Median \\
\hline Diagnostic mammography & $\$ 349(\$ 492)$ & $\$ 234$ \\
Tomosynthesis & $\$ 134(\$ 102)$ & $\$ 113$ \\
Ultrasound & $\$ 132(\$ 134)$ & $\$ 95$ \\
Molecular breast imaging & $\$ 296(\$ 422)$ & $\$ 135$ \\
Magnetic resonance imaging & $\$ 1,197(\$ 1,054)$ & $\$ 1,021$ \\
Biopsy & $\$ 1,938(\$ 2,343)$ & $\$ 1,211$ \\
Surgical biopsy & & \\
$\quad$ Ultrasound-guided localization & $\$ 1,909(\$ 2,199)$ & $\$ 1,245$ \\
$\quad$ Other surgical procedures & $\$ 356(\$ 675)$ & $\$ 193$ \\
FNA biopsy & & \\
$\quad$ Ultrasound-guided FNA & $\$ 249(\$ 467)$ & $\$ 153$ \\
$\quad$ Other FNA & $\$ 217(\$ 286)$ & $\$ 172$ \\
Core biopsy & & \\
$\quad$ Ultrasound-guided core & $\$ 1,032(\$ 1,200)$ & $\$ 694$ \\
Procedures ancillary to biopsy & & \\
$\quad$ Follow-up office visit & $\$ 735(\$ 891)$ & $\$ 451$ \\
$\quad \begin{array}{l}\text { Pathology } \\
\text { Anesthesia }\end{array}$ & $\$ 1,264(\$ 2,463)$ & $\$ 501$ \\
\hline
\end{tabular}

Notes: aDue to billing code inconsistencies for differentiation of biopsy types, some payments were not included when reporting by specific biopsy type, but were included in the overall mean (SD) costs for all biopsies.

Abbreviation: FNA, fine needle aspiration.

$\$ 2.8$ billion. ${ }^{16}$ In this study, we did not determine whether there was a breast cancer diagnosis following any diagnostic procedure, so estimates of false-positives were derived from other published reports. The discrepancy between estimated volumes of post-screening mammogram procedures performed and reported cancer incidence rates in view of their positive predictive value suggests considerable unmet medical need for more sensitive and specific breast diagnostic tools.

Our data provide mean and median unit costs for each of the procedures and ancillary services, derived from a large nationally representative database composed of real-world medical claims across a wide range of providers, health plans, and patients in commercially insured and Medicare-covered populations. The unit costs we derived for breast cancer diagnostic procedures may be of value for other researchers and managed care organizations to use in examining the costs of breast diagnostic services. Other studies to date have provided costs in aggregate, with or without including accompanying (ancillary) or follow-up services, and some only for specific payers such as Medicare. ${ }^{16,27,28}$ Costs for patients under the age of 65 years are a large portion of the overall national health care expenditure, especially considering the median age at diagnosis of 61 years and an estimated $57.7 \%$ of new cases occurring in patients aged 18-64 years. ${ }^{3,29}$ The costs presented in this paper provide a broad national average of commercially insured expenditure rates. According to the US Centers for Disease Control and Prevention, 73.4\% of women with health care coverage age 40-64 years received a mammogram within a 2-year window (2013 data). ${ }^{30}$ This is a large population to consider in view of the health care resource use and expenditure by health plans, and we believe our data are relevant to that population.

Breast cancer screening remains a controversial clinical, public health, and social issue. Data on the frequencies and costs of breast cancer diagnostic procedures are sparse, with many prior studies relying on Medicare records that pertain primarily to older segments of the affected populations and typically lower expenditure rates for procedures. ${ }^{28,31}$ The risks and high costs of these diagnostic procedures point to unmet medical need, especially for technological advancements and quality initiatives that could minimize unnecessary invasive procedures, reduce costs, and optimize patient care for women during their breast diagnostic journey.

\section{Limitations}

This study is subject to several limitations. Misclassification error is possible when relying on procedure and diagnosis coding from health care claims in the absence of patient charts or provider attestations, where the extent of data entry error, undercoding, or overcoding is unknown. Patients' medical history was limited to health care claims during the reporting years in this study, such that comorbidities or other sociodemographic factors outside of this data were unknown. Coding of diagnostic radiologic procedures may be subject to data coding limitations as well as coding changes and revised code definitions that occurred during the time of the study. BI-RADS information is lacking in the MarketScan administrative claims data. Similarly, clinicians' rationales for use of various diagnostic procedures and evidence of whether patients were symptomatic or asymptomatic are not found in claims data. The distinction between screening and diagnostic ultrasound procedures and criteria for dense breast tissue in distinguishing screening versus diagnostic ultrasounds are not available using standard reimbursement codes, and our ability to make this distinction using sequencing of events or other algorithms is limited. Unmeasurable characteristics of patients with different diagnostic pathways or progressions, such as the patient's income level, proximity and availability of diagnostic services or specialists, family situation (e.g., support network, spouse, dependents), and other sociodemographic factors, may account for the differences found in health care costs and utilization. Controlling for specific 
comorbidities, overall comorbidity burden, or other clinical characteristics was beyond the scope of this study, but should be considered for future investigations. Similarly, we did not examine outcomes related to the end point of positive breast cancer diagnosis, another consideration for future research. This study was a convenience sample of individuals in the US with commercial health coverage or private Medicare supplemental coverage, and consequently, results of this analysis may not be generalizable to patients with other insurance, without health insurance coverage, or to international populations.

\section{Conclusion and take-home points}

The breast imaging care path is a critical component in diagnosing breast cancer in the USA. An estimated 12,394,432 patients in the USA during the period 2012-2015 annually received 8,732,909 diagnostic mammograms, 6,987,399 breast ultrasounds, and 1,585,856 biopsies, contributing to annual expenditure of $\$ 7.91$ billion for follow-on breast diagnostic procedures in the USA. Breast biopsy, with average payments of $\$ 1,938$, not including ancillary services, has shown falsepositive rates in the USA estimated at $71.0 \%$, representing annual false-positive expenditures of $\$ 2.18$ billion. An estimated $49.4 \%$ of all breast diagnostic patients were recalled for a second diagnostic procedure, $20.1 \%$ had three diagnostic procedures, and $10.0 \%$ had four diagnostic procedures, further underscoring the volume and expense of patient recalls to address conscientious clinicians' uncertainty for positive diagnosis using the current arsenal of diagnostic procedures. Although the technologies have evolved, diagnostic modalities providing better specificity and greater diagnostic confidence can have great potential impact on lowering health care expenditures and shortening the patient's diagnostic journey.

\section{Acknowledgments}

The authors gratefully acknowledge the key contributions of Douglas Weldon (Truven Health Analytics) for his work in defining, extracting, and assembling the data. This study was sponsored by Seno Medical Instruments, Inc., San Antonio, TX, USA.

\section{Disclosure}

Anna Vlahiotis, Brian Griffin, and Jay Margolis are employees of Truven Health Analytics, an IBM company, which was paid by Seno Medical Instruments in connection with the development of this paper. Thomas Stavros is an employee of Seno Medical Instruments. The authors report no other conflicts of interest in this work.

\section{References}

1. DeSantis CE, Fedewa SA, Goding Sauer A, Kramer JL, Smith RA, Jemal A. Breast cancer statistics, 2015: convergence of incidence rates between black and white women. CA Cancer J Clin. 2016;66(1):31-42.

2. Centers for Disease Control and Prevention. Cancer among women. Updated June 16, 2016. Available from: http://www.cdc.gov/cancer/ dcpc/data/women.htm. Accessed October 22, 2016.

3. SEER Cancer Stat Facts: Female Breast Cancer. National Cancer Institute. Bethesda, MD. Available from: http://seer.cancer.gov/statfacts/ html/breast.html. Accessed January 23, 2017.

4. Berry DA, Cronin KA, Plevritis SK, et al. Effect of screening and adjuvant therapy on mortality from breast cancer. $N$ Engl J Med. 2005; 353(17):1784-1792.

5. Nelson HD, Tyne K, Naik A, Bougatsos C, Chan BK, Humphrey L; U.S. Preventive Services Task Force. Screening for breast cancer: an update for the U.S. Preventive Services Task Force. Ann Intern Med. 2009;151(10):727-737, W237-42.

6. Blumen H, Fitch K, Polkus V. Comparison of treatment costs for breast cancer, by tumor stage and type of service. Am Health Drug Benefits. 2016;9(1):23-32.

7. Lee CH, Dershaw DD, Kopans D,et al. Breast cancer screening with imaging: recommendations from the society of breast imaging and the ACR on the use of mammography, breast MRI, breast ultrasound, and other technologies for the detection of clinically occult breast cancer. J Am Coll Radiol. 2010;7(1):18-27.

8. Mainiero MB, Lourenco A, Mahoney MC, et al. ACR appropriateness criteria breast cancer screening. J Am Coll Radiol. 2016;13(11S): R45-R49.

9. Oeffinger KC, Fontham ET, Etzioni R, et al. Breast cancer screening for women at average risk: 2015 guideline update from the American Cancer Society. JAMA. 2015;314(15):1599-1614.

10. American Cancer Society. American Cancer Society Guidelines for the early detection of cancer. Available from: http://www.cancer.org/healthy/ findcancerearly/cancerscreeningguidelines/american-cancer-societyguidelines-for-the-early-detection-of-cancer. Accessed October 22, 2016.

11. National Comprehensive Cancer Network. NCCN Clinical Practice Guideline in Oncology: Breast Cancer Screening and Diagnosis. Version 1.2016, 07/26/16. Available from: https://www.nccn.org/store/ login/login.aspx?ReturnURL=https://www.nccn.org/professionals/ physician_gls/pdf/breast-screening.pdf. Accessed January 23, 2017.

12. Siu AL; U.S. Preventive Services Task Force. Screening for breast cancer: U.S. preventive services task force recommendation statement. Ann Intern Med. 2016;164(4):279-296.

13. Nelson HD, Cantor A, Humphrey L, et al. MSUS Preventive Services Task Force. Evidence Summary: Screening for Breast Cancer. Effectiveness of Breast Cancer Screening: Systematic Review and Meta-Analysis to Update the 2009 U.S. Preventive Services Task Force Recommendation. Available from: https://www.uspreventiveservicestaskforce. org/Page/Document/evidence-summary-screening-for-breast-cancer/ breast-cancer-screening1. Accessed January 23, 2017.

14. National Committee for Quality Assurance. 2016 State of health care quality: Breast Cancer Screening. Available from: http://www.ncqa. org/report-cards/health-plans/state-of-health-care-quality/2016-tableof-contents/breast-cancer. Accessed January 23, 2017.

15. Bleyer A, Welch HG. Effect of three decades of screening mammography on the incidence of breast cancer. N Engl J Med. 2012;367(21): 1998-2005.

16. Ong MS, Mandl KD. National expenditure for false-positive mammograms and breast cancer overdiagnoses estimated at $\$ 4$ billion a year. Health Aff (Millwood). 2015;34(4):576-583.

17. Rabinovich K, Kaplan S, Carcano C, Nadjafi L, Salom I. Double reading of screening mammography: effect on reducing false positive rates. Presentation delivered May 16, 2016, at the American College of Radiology Annual Meeting (ACR 2016) in Washington, DC, USA. Available at https://www.acr.org/ /media/ACR/Documents/PDF/ Annual-Meeting/Abstracts/2016/16079/16079_Rabinovich.pdf?la=en. Accessed January 23, 2017. 
18. Grabler P, Sighoko D, Wang L, Allgood K, Ansell D. Recall and cancer detection rates for screening mammography: finding the sweet spot. AJR Am J Roentgenol. 2017;208(1):208-213.

19. Barry M, Gemignani ML. Follow-Up for Women with Abnormal Mammograms. NEJM Journal Watch, Women's Health, April 14, 2011. Available from: http://www.jwatch.org/wh201104140000001/2011/04/14/ follow-women-with-abnormal-mammograms. Accessed January 23, 2017.

20. NCI-funded Breast Cancer Surveillance Consortium (HHSN261201100031C). Downloaded from the Breast Cancer Surveillance Consortium Web site - http://breastscreening.cancer.gov/. http://www.bcsc-research. org/statistics/performance/. Accessed January 23, 2017.

21. Chae EY, Cha JH, Shin HJ, Choi WJ, Kim HH. Reassessment and follow-up results of BI-RADS Category 3 lesions detected on screening breast ultrasound. AJR Am J Roentgenol. 2016;206(3):666-672.

22. Sia J, Moodie K, Bressel M, et al. A prospective study comparing digital breast tomosynthesis with digital mammography in surveillance after breast cancer treatment. Eur J Cancer. 2016;61:122-127.

23. American College of Radiology. Breast Imaging Reporting and Data System $^{\circledR}$ (BI-RADS ${ }^{\circledR}$ ). Reston, VA: American College of Radiology. 1998.

24. Hubbard RA, Kerlikowske K, Flowers CI, Yankaskas BC, Zhu W, Miglioretti DL. Cumulative probability of false-positive recall or biopsy recommendation after 10 years of screening mammography: a cohort study. Ann Intern Med. 2011;155(8):481-492.
25. United States Census Bureau. Geographic Terms and Concepts - Census Divisions and Census Regions. Available from: https://www.census. gov/geo/reference/gtc/gtc_census_divreg.html. Accessed January 23, 2017.

26. Mihaylova B, Briggs A, O'Hagan A, Thompson SG. Review of statistical methods for analysing healthcare resources and costs. Health Econ. 2011;20(8):897-916.

27. Gutwein LG, Ang DN, Liu H, et al. Utilization of minimally invasive breast biopsy for the evaluation of suspicious breast lesions. Am J Surg. 2011;202(2):127-132.

28. Gross CP, Long JB, Ross JS, et al. The cost of breast cancer screening in the medicare population. JAMA Intern Med. 2013;173(3): 220-226.

29. Welch HG, Gorski DH, Albertsen PC. Trends in metastatic breast and prostate cancer-lessons in cancer dynamics. NEngl J Med. 2015;373(18): 1685-1687.

30. National Center for Health Statistics. Health, United States, 2015: With Special Feature on Racial and Ethnic Health Disparities. Table 70. Hyattsville, MD. 2016. Available from: https://www.cdc.gov/nchs/ data/hus/hus15.pdf\#070. Accessed January 23, 2017.

31. Elmore JG, Gross CP. The cost of breast cancer screening in the United States: a picture is worth... a billion dollars? Ann Intern Med. 2014;160(3):203. 


\section{Supplementary materials}

Table SI Mean (SD) and median paid amounts for breast diagnostic procedures, all patients and by payer, in US dollars

\begin{tabular}{|c|c|c|c|c|c|c|c|c|}
\hline & \multicolumn{2}{|l|}{$\begin{array}{l}\text { All patients } \\
N=875,526\end{array}$} & \multicolumn{2}{|l|}{$\begin{array}{l}\text { Commerciala }^{a} \\
n=789,062\end{array}$} & \multicolumn{2}{|l|}{$\begin{array}{l}\text { Medicare }^{b} \\
n=73,768\end{array}$} & \multicolumn{2}{|l|}{$\begin{array}{l}\text { Transitionc } \\
n=12,696\end{array}$} \\
\hline & Mean (SD) & Median & Mean (SD) & Median & Mean (SD) & Median & Mean (SD) & Median \\
\hline Diagnostic mammography & $\$ 349(\$ 492)$ & $\$ 234$ & $\$ 354(\$ 490)$ & $\$ 239$ & $\$ 297(\$ 5 \mid 8)$ & $\$ 172$ & $\$ 347(\$ 477)$ & $\$ 229$ \\
\hline Tomosynthesis & $\$ 134(\$ 102)$ & $\$ 113$ & $\$ 136(\$ 102)$ & $\$ 115$ & $\$ 110(\$ 102)$ & $\$ 93$ & $\$ 115(\$ 88)$ & $\$ 93$ \\
\hline Ultrasound & $\$ 132(\$ 134)$ & $\$ 95$ & $\$ 137(\$ 135)$ & $\$ 100$ & $\$ 76(\$ 109)$ & $\$ 54$ & $\$ 112(\$ 120)$ & $\$ 83$ \\
\hline Molecular breast imaging & $\$ 296(\$ 422)$ & $\$ 135$ & $\$ 299(\$ 406)$ & $\$ 133$ & $\$ 291(\$ 530)$ & $\$ 190$ & $\$ 175(\$ 165)$ & $\$ 77$ \\
\hline Magnetic resonance imaging & $\$ 1,197(\$ 1,054)$ & $\$ 1,021$ & $\$ 1,228(\$ 1,054)$ & $\$ 1,073$ & $\$ 875(\$ 1,005)$ & $\$ 615$ & $\$ 1,130(\$ 984)$ & $\$ 954$ \\
\hline Biopsy & $\$ 1,938(\$ 2,343)$ & $\$ 1,211$ & $\$ 1,940(\$ 2,177)$ & $\$ 1,246$ & $\$ 1,901(\$ 3,424)$ & $\$ 918$ & $\$ 2,064(\$ 2,862)$ & $\$ 1,154$ \\
\hline \multicolumn{9}{|l|}{ Surgical biopsy } \\
\hline Ultrasound-guided localization & $\$ 1,909(\$ 2,199)$ & $\$ 1,245$ & $\$ 1,902(\$ 2,002)$ & $\$ 1,276$ & $\$ 1,951(\$ 3,438)$ & $\$ 971$ & $\$ 2,075(\$ 2,466)$ & $\$ 1,105$ \\
\hline Other surgical procedures & $\$ 356(\$ 675)$ & $\$ 193$ & $\$ 361(\$ 676)$ & $\$ 203$ & $\$ 290(\$ 599)$ & $\$ 155$ & $\$ 502(\$ 993)$ & $\$ 236$ \\
\hline \multicolumn{9}{|l|}{ FNA biopsy } \\
\hline Ultrasound-guided FNA & $\$ 249(\$ 467)$ & $\$ 153$ & $\$ 25 I(\$ 467)$ & $\$ 154$ & $\$ 240(\$ 480)$ & $\$ 146$ & $\$ 208(\$ 406)$ & $\$ 118$ \\
\hline Other FNA & $\$ 217(\$ 286)$ & $\$ 172$ & $\$ 220(\$ 298)$ & $\$ 173$ & $\$ 193(\$ 135)$ & $\$ 159$ & $\$ 173(\$ 82)$ & $\$ 181$ \\
\hline \multicolumn{9}{|l|}{ Core biopsy } \\
\hline Ultrasound-guided core & $\$ 1,032(\$ 1,200)$ & $\$ 694$ & $\$ 1,036(\$ 1,077)$ & $\$ 7 / 2$ & $\$ 999(\$ 1,950)$ & $\$ 578$ & $\$ I, 04 I(\$ I, 407)$ & $\$ 695$ \\
\hline \multicolumn{9}{|l|}{ Procedures ancillary to biopsy } \\
\hline Follow-up office visit & $\$ 735(\$ 89 \mid)$ & $\$ 451$ & $\$ 720(\$ 886)$ & $\$ 432$ & $\$ 811$ (\$926) & $\$ 570$ & $\$ 783(\$ 807)$ & $\$ 516$ \\
\hline Pathology & $\$ 1,264(\$ 2,463)$ & $\$ 501$ & $\$ 1,243(\$ 2,37 I)$ & $\$ 502$ & $\$ 1,381(\$ 3,075)$ & $\$ 471$ & $\$ 1,682(\$ 2,882)$ & $\$ 660$ \\
\hline Anesthesia & $\$ 1,120(\$ 1, \mid 46)$ & $\$ 776$ & $\$ 1,178(\$ 1, \mid 43)$ & $\$ 843$ & $\$ 702(\$ 1,058)$ & $\$ 356$ & $\$ 1,166(\$ 1,3 \mid 2)$ & $\$ 793$ \\
\hline
\end{tabular}

Notes: a Commercial: data from active employees, early retirees, health care coverage under the Consolidated Omnibus Budget Reconciliation Act of 1985 continues, and

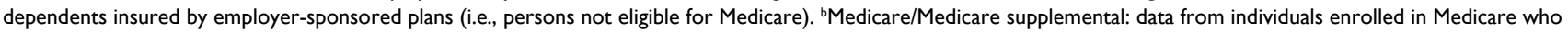
also have group health insurance coverage paid for by a current or former employer. 'Transition: data for patients who transitioned during the reporting period from having only commercial insurance to then having Medicare plus a supplemental insurance paid for by their current or former employer.

Abbreviation: FNA, fine needle aspiration.

ClinicoEconomics and Outcomes Research

\section{Publish your work in this journal}

ClinicoEconomics and Outcomes Research is an international, peerreviewed open-access journal focusing on health technology assessment, pharmacoeconomics and outcomes research in the areas of diagnosis, medical devices, and clinical, surgical and pharmacological intervention. The economic impact of health policy and health systems organization also constitute important areas of coverage. The manuscript management system is completely online and includes a very quick and fair peer-review system, which is all easy to use. Visit http://www.dovepress.com/testimonials.php to read real quotes from published authors. 